\title{
Research
}

\section{Musculoskeletal clinical assessment and treatment services at the primary-secondary care interface:}

\section{an observational study}

\begin{abstract}
Background

Management of musculoskeletal conditions

in the UK is increasingly delivered in

multidisciplinary clinical assessment and treatment services (CATS) at the primarysecondary care interface. However, there is little evidence concerning the characteristics and management of patients attending CATS.
\end{abstract}

\section{Aim}

To describe the characteristics, investigation, and treatment of adults attending a musculoskeletal CATS.

\section{Design and setting}

Cross-sectional analysis of cohort study baseline data from a musculoskeletal CATS in Stoke-onTrent Primary Care Trust, UK.

\section{Method}

All patients referred from primary care between February 2008 and June 2009 were mailed a pre-consultation questionnaire concerning pain duration, general health status, anxiety, depression, employment status, and work absence due to musculoskeletal problems. At the consultation, clinical diagnoses, body region(s) affected, investigations, and treatment were recorded.

\section{Results}

A total of 2166 (73\%) completed questionnaires were received. Chronic pain duration $>1$ year (55\%), major physical limitation (76\%), anxiety (49\%), and depression (37\%) were common. O those currently employed, 516 (45\%) had taken time off work in the last 6 months because of their musculoskeletal problem; 325 (29\%) were unable to do their usual job. The most frequent investigations were $\mathrm{X}$-rays (23\%), magnetic resonance imaging $(18 \%)$, and blood tests (14\%): $1012(48 \%)$ received no investigations. Injections were performed in $282(13 \%)$ and 492 (23\%) were referred to physiotherapy.

\section{Conclusion}

Although most patients presented with musculoskeletal problems suitable for CATS, chronic pain, physical limitation, anxiety, depression, and work disability were commonplace, highlighting the need for a biopsychosocial model of care that addresses psychological, social, and work-related needs, as well as pain and physical disability.

\section{Keywords}

anxiety; depression; health services; musculoskeletal diseases; referral and consultation; work disability.

\section{INTRODUCTION}

Musculoskeletal disorders such as back pain and osteoarthritis are highly prevalent and frequently lead to consultation in primary care, ${ }^{1,2}$ where most are managed. They comprised a considerable proportion of the $€ 16.8$ billion that sickness absence from work cost the UK economy in 2009 . at an average of 6.4 working days lost per employee. ${ }^{3}$ Back pain is the most common cause of long-term work absence in manual workers, followed by mental health problems, and other musculoskeletal disorders, and is the third most common cause of long-term work absence among non-manual workers. ${ }^{3}$ Dame Carol Black's report Working for a Healthier Tomorrow advocates retention in, or return to, work to be a key indicator of the successful treatment of working-age people. ${ }^{4}$ Achieving this for the large numbers of patients with musculoskeletal problems poses a major challenge.

For patients with musculoskeletal problems, referral for a specialist opinion has traditionally been to orthopaedic or rheumatology services in secondary care. Recent UK governmental policy has emphasised provision of patientcentred care in services designed around individuals' needs, which build partnerships between hospitals and general practice. Management of musculoskeletal

E Roddy, DM, FRCP, clinical senior lecturer in rheumatology and consultant rheumatologist; SL Hider, PhD, FRCP, clinical senior lecturer in rheumatology and consultant rheumatologist; J Packham: DM, FRCP, consultant rheumatologist and senior lecturer in rheumatology; EM Hay, MD, FRCP, professor of community rheumatology; Arthritis Research UK Primary Care Centre,

Keele University, Keele and Staffordshire

Rheumatology Centre, Haywood Hospital, Stokeon-Trent. I Zwierska; PhD, research fellow/ programme manager; KP Jordan, PhD, reader in biostatistics; Arthritis Research UK Primary Care Centre, Keele University, Keele. P Dawes, FRCP, consultant rheumatologist, Staffordshire Rheumatology Centre, Haywood Hospital, Stokeon-Trent. K Stevenson, MPhil, MCSP, consultant conditions has shifted away from secondary care towards multidisciplinary clinical assessment and treatment services (CATS) at the primary-secondary care interface. ${ }^{6}$ CATS act as a 'one-stop shop' for efficient, rapid assessment, diagnosis, and treatment of patients, yet, crucially, they are also intended to provide holistic care, addressing patients' psychological, social, and physical needs to enable them to continue working. ${ }^{6}$ However, there is limited evidence concerning the characteristics of patients referred to CATS, which is needed to inform appropriate resourcing. For example, it is not known whether the majority of patients have simple regional musculoskeletal complaints amenable to treatment with traditional biomedical approaches, or whether they are frequently complicated by chronic symptoms, widespread pain, and psychosocial distress.

Therefore, a prospective cohort study was carried out of patients referred to a musculoskeletal CATS in North Staffordshire, which were cited as an example of good practice in the Department of Health's Musculoskeletal Services Framework. ${ }^{6}$ Using baseline data from this cohort, this article describes the musculoskeletal problems addressed in the CATS consultation and the prevalence of physical disability, anxiety, depression, and musculoskeletal-related work absence. physiotherapist, Physiotherapy Department, University Hospital of North Staffordshire, Stokeon-Trent.

\section{Address for correspondence}

Edward Roddy, Arthritis Research UK Primary Care Centre, Primary Care Sciences, Keele University, Keele, Staffordshire, ST5 5BG.

E-mail: e.roddyacphc.keele.ac.uk

Submitted: 18 May 2012; Editor's response: 19 July 2012; final acceptance: 5 October 2012. (CBritish Journal of General Practice

This is the full-length article (published online 28 Jan 2013) of an abridged version published in print. Cite this article as: $\mathbf{B r} \mathbf{J}$ Gen Pract 2013. DOI: 10.3399/bjgp13X663109 


\section{How this fits in}

Management of musculoskeletal conditions in the UK has shifted away from secondary care towards multidisciplinary clinical assessment and treatment services (CATS) at the primary-secondary care interface. Although most patients are referred with regional musculoskeletal problems that are appropriate for management in CATS, chronic pain, impaired physical function, anxiety, depression, and work disability are highly prevalent. Musculoskeletal CATS should provide a holistic biopsychosocial model of care that identifies and addresses psychosocial needs and work disability, in addition to pain and physical disability.

\section{METHOD}

This study was undertaken using baseline data from a cohort study. ${ }^{7}$ All participants provided written informed consent.

\section{Study setting}

Stoke-on-Trent Primary Care Trust (PCT) serves a population of more than 270000 people. Since the mid-1990s, the PCT has run a multidisciplinary musculoskeletal service at the primary-secondary care interface, to which secondary care musculoskeletal referrals are triaged following clinical review of referral letters to musculoskeletal, rheumatology, and orthopaedic services. The musculoskeletal service is the preferred provider for patients with non-surgical, noninflammatory musculoskeletal problems. The triage process aims to manage musculoskeletal conditions requiring nonsurgical interventions in the community, while appropriate cases are directed to rheumatology or orthopaedic services.

\section{Data collection}

All adults aged $\geq 18$ years seen at this musculoskeletal CATS between February 2008 and June 2009 were invited to participate in the study. Patients were mailed a health questionnaire 2 weeks before the CATS appointment and asked to bring the completed questionnaire with them when they attended clinic. All participants were seen by a research assistant when they attended for the CATS appointment and were given a further opportunity to participate in the study if they had not brought the baseline questionnaire with them. The clinician undertaking the CATS consultation did not have access to the completed health questionnaire.
The questionnaire contained validated health assessment instruments including the Medical Outcomes Study (MOS) Short Form-36 (SF-36) version 2, ${ }^{8}$ Hospital Anxiety and Depression Scale (HADS), ${ }^{9}$ and pain duration. ${ }^{10}$ Data were collected regarding age, sex, postcode, marital status, selfreported height/weight, smoking history (categorised as current, previous, or never), current employment status, absence from work in the preceding 6 months because of musculoskeletal problems, and current work status (categorised as doing usual job, working fewer hours, doing lighter duties, on paid/unpaid sick leave).

Clinical diagnosis (including pain location) addressed during the CATS consultation, investigations requested, treatment prescribed, onward referral, and discharge/ follow-up plans were recorded by the clinician conducting the consultation.

\section{Analysis}

Age, sex, and neighbourhood deprivation scores, based on the Index of Multiple Deprivation 2007, ${ }^{11}$ were compared between study participants and non-participants. Non-participants included those who did not attend their CATS appointment and those who attended but did not wish to participate. Age, sociodemographic data, smoking status, and body mass index (BMI) were summarised for study participants as a whole.

Participants were categorised into four mutually exclusive groups according to the location(s) of the problem addressed in the CATS consultation: upper limb/neck only, spine only, lower limb only, or multiple sites. Pain was considered to be multisite when the clinician recorded either more than one location lupper limb/neck, spine, lower limb) or a diagnosis of fibromyalgia, chronic widespread pain, generalised osteoarthritis, or polymyalgia rheumatica.

Investigations requested, joint injections performed, referral to physiotherapy and pain clinics, and discharge/follow-up planning ldischarged to GP, follow-up appointment made, follow-up appointment pending results of investigations) were summarised and compared by pain location lupper limb/neck only, spine only, lower limb only, or multiple sites), using $\chi^{2}$ tests.

Pain duration was categorised as less than 3 months, 3-12 months, 1-2 years, $3-10$ years, and $>10$ years. Mean scores and standard deviations (SDs) for the eight domains of the SF-36 were calculated and normalised, using the general population mean of $50(S D=10)$ and the conventional scoring. ${ }^{8}$ Major physical limitation was 


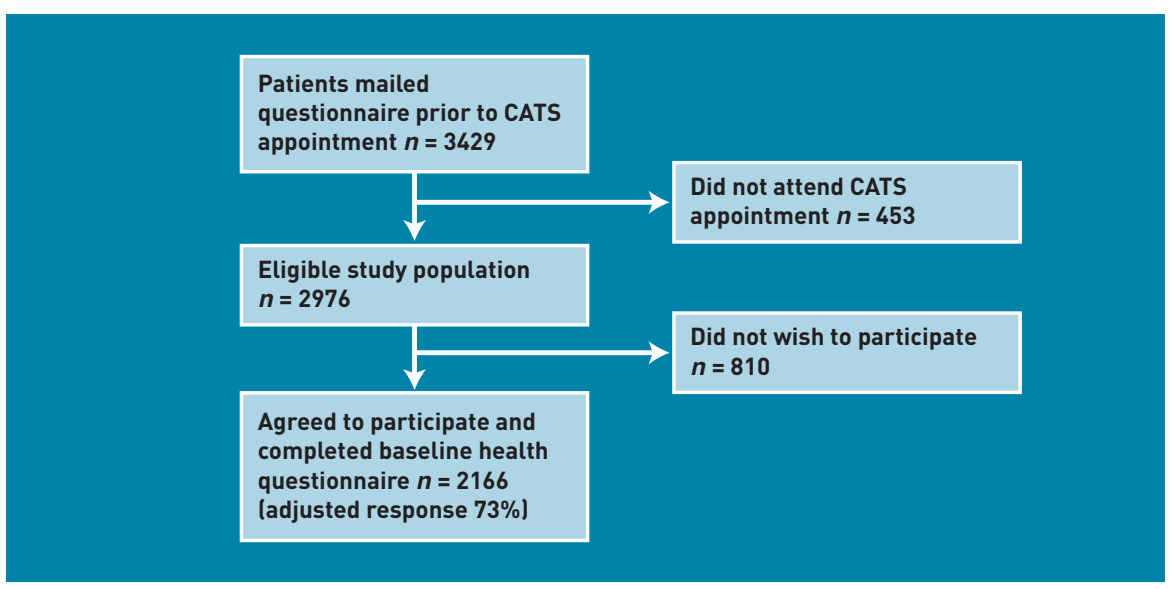

Figure 1. Flow of participants through the study.

defined as responding 'Yes, limited a lot', the worst response category, to any one of the 10 items comprising the SF-36 physical function scale (PF-10). ${ }^{12}$ Probable anxiety and depression were defined as a score of $>11$ on the anxiety and depression subscales of the HADS respectively: scores 8-10 were considered borderline.?

Current employment was defined as either having a full-time or part-time paid job, or being employed but being currently off sick for 6 months or less. Among those in current employment, the proportions of participants who reported time off work during the preceding 6 months because of

\section{Table 1. Sociodemographic data, smoking status, and body mass index of the cohort}

\begin{tabular}{|c|c|}
\hline \multicolumn{2}{|l|}{ Characteristic, total $n=2166$} \\
\hline Age in years, mean (SD) & $51.1(15.2)$ \\
\hline \multicolumn{2}{|l|}{ Age group, years, $n[\%]$} \\
\hline $18-44$ & 750 (35) \\
\hline 45-64 & $992(46)$ \\
\hline$\geq 65$ & $424(20)$ \\
\hline Female, $n(\%)$ & $1238(57)$ \\
\hline \multicolumn{2}{|l|}{ Living arrangements, $n(\%)$} \\
\hline Married/cohabiting & $1530(71)$ \\
\hline Living alone & $322(15)$ \\
\hline \multicolumn{2}{|l|}{$\mathrm{BMI}, n(\%)^{\mathrm{a}}$} \\
\hline Normal/underweight (<25 kg/m²) & $631(30)$ \\
\hline Overweight $\left(25-30 \mathrm{~kg} / \mathrm{m}^{2}\right)$ & $792(38)$ \\
\hline Obese $\left(\geq 30 \mathrm{~kg} / \mathrm{m}^{2}\right)$ & 674 (32) \\
\hline \multicolumn{2}{|l|}{ Smoking status, $n(\%)$} \\
\hline Never smoked & $989(46)$ \\
\hline Previously smoked & 682 (32) \\
\hline Current smoker & 493 (23) \\
\hline \multicolumn{2}{|c|}{$\begin{array}{l}\text { BMI }=\text { body mass index }{ }^{a} B M I \text { data were missing } \\
\text { for } 69 \text { (3\%) participants. Missing data for all other } \\
\text { variables }<1 \% \text {. }\end{array}$} \\
\hline
\end{tabular}

musculoskeletal problems, and currently not doing their usual job lworking fewer hours, doing lighter duties, or being on paid or unpaid sick leave) were calculated.

The proportion of participants within each category of pain duration, and those reporting major physical limitation, anxiety, depression, and work absence were calculated for the whole study population, with $95 \%$ confidence intervals (Cls).

\section{Sample size}

Sample size was based on the number of patients (approximately 3500) who are referred to the musculoskeletal and back pain interface clinics in Stoke-on-Trent PCT during the course of a year. Based on the authors previous studies, it was expected that $75 \%$ of those invited to the study would participate. ${ }^{13}$ The resulting sample size of 2500 would, for example, allow a $95 \% \mathrm{Cl}$ of $\pm 2 \%$, based on estimated prevalences of $50 \%$ for chronic pain and major physical limitation.

\section{RESULTS}

A total of 3429 patients were mailed the questionnaire; 453 (13\%) did not attend their CATS appointment. Of the remainder, 2166 completed questionnaires were received ladjusted response 73\%) (Figure 1).

\section{Sociodemographics}

There were no differences in mean age or median neighbourhood deprivation scores between those who participated and those who did not take part or did not attend. However, there was a lower percentage of males in the group who participated $143 \%$ versus $47 \%, P=0.011$ ).

The sociodemographic characteristics, smoking status, and BMI of participants are shown in Table 1. 


\section{Table 2. Most frequent diagnoses made at each joint site}

\begin{tabular}{|c|c|c|c|c|c|c|c|}
\hline \multicolumn{2}{|l|}{ Neck, $n(\%)$} & \multicolumn{2}{|l|}{ Shoulder, $n(\%)$} & \multicolumn{2}{|l|}{ Elbow, $n(\%)$} & \multicolumn{2}{|l|}{ Hand and wrist, $n(\%)$} \\
\hline Total & 183 & Total & 291 & Total & 68 & Total & 233 \\
\hline Neck pain without referral to the arm & $151(83)$ & $\begin{array}{l}\text { Subacromial } \\
\text { pathology }\end{array}$ & 179 (62) & Epicondylitis & $45(66)$ & $\begin{array}{l}\text { Carpal tunnel } \\
\text { syndrome }\end{array}$ & $95(41)$ \\
\hline Neck pain with referral to the arm & $36(20)$ & $\begin{array}{l}\text { Glenohumeral OA/ } \\
\text { frozen shoulder }\end{array}$ & $78(27)$ & Other & 24 (35) & $\begin{array}{l}\text { OA (nodal, radiocarpal, } \\
\text { first CMCJ) }\end{array}$ & $58(25)$ \\
\hline \multirow[t]{2}{*}{ Other } & $9(5)$ & Acromioclavicular OA & $40(14)$ & & & $\begin{array}{l}\text { Tendon problems (trigger } \\
\text { finger, de Quervains' } \\
\text { tenosynovitis) }\end{array}$ & $48(21)$ \\
\hline & & Other & $23(8)$ & & & Other & $45(19)$ \\
\hline Spine, $\mathrm{n}(\%)$ & & Hip, $n(\%)$ & & Knee, $n(\%)$ & & Foot and ankle, $n(\%)$ & \\
\hline Total & 615 & Total & 142 & Total & 514 & Total & 141 \\
\hline $\begin{array}{l}\text { Low back pain without referral } \\
\text { to the leg }\end{array}$ & $286(47)$ & $\mathrm{OA}$ & 75 (53) & $\mathrm{OA}$ & $289(56)$ & $\begin{array}{l}\text { Achilles pathology } \\
\text { and plantar fasciitis }\end{array}$ & $42(30)$ \\
\hline Low back pain with referral to the leg & $233(38)$ & Trochanteric bursitis & $40(28)$ & Menisceal pathology & $114(22)$ & $\begin{array}{l}\text { Ankle problems } \\
\text { (ligament injury, instability, } \\
\text { tendonitis/tendinopathy) }\end{array}$ & 38 (27) \\
\hline Spinal stenosis & $41(7)$ & Other & $31(22)$ & Anterior knee pain & $43(8)$ & Mid-foot OA/flat feet & $29(20)$ \\
\hline \multirow[t]{2}{*}{ Other } & 79 (13) & & & $\begin{array}{l}\text { Ligament pathology } \\
\text { (cruciate, collateral) }\end{array}$ & $41(8)$ & $\begin{array}{l}\text { Forefoot problems } \\
\text { (Morton's neuroma, } \\
\text { hallux valgus, } \\
\text { first MTPJ OA) }\end{array}$ & $23(16)$ \\
\hline & & & & Other & $75(15)$ & Other & $24(17)$ \\
\hline
\end{tabular}

CMCJ = carpometacarpal joint. MTPJ = metatarsophalangeal joint. OA = osteoarthritis. ${ }^{a}$ Column totals add up to greater than $100 \%$ as some participants have more than one diagnosis recorded.

Table 3. Frequency of investigations, interventions, referrals, and follow-up by location of the problem

\begin{tabular}{|c|c|c|c|c|c|c|}
\hline & Total & Upper limb/neck & Spine & Lower limb & Multiple $^{a}$ & $P$-value \\
\hline$n$ & 2130 & 607 & 537 & 656 & 221 & \\
\hline \multicolumn{7}{|l|}{ Investigations, $n$ (\%) } \\
\hline$X$-ray & $475(22)$ & $146(24)$ & $45(8)$ & $174(27)$ & 74 (33) & $<0.001$ \\
\hline MRI & $393(18)$ & $47(8)$ & $199(37)$ & $124(19)$ & $14(6)$ & $<0.001$ \\
\hline Blood test & $308(14)$ & $78(13)$ & $69(13)$ & $48(7)$ & 70 (32) & $<0.001$ \\
\hline Electrophysiological tests & $138(6)$ & $108(18)$ & $5(<1)$ & $2(<1)$ & $17(8)$ & $<0.001$ \\
\hline Ultrasound & $96(5)$ & $62(10)$ & $3 \mid<1)$ & $21(3)$ & $4(2)$ & $<0.001$ \\
\hline No investigation & 1012 (48) & $281(46)$ & $276(51)$ & $328(50)$ & 86 (39) & 0.009 \\
\hline \multicolumn{7}{|c|}{ Interventions and referrals, $n[\%]$} \\
\hline Injection & $282(13)$ & $152(25)$ & $7(1)$ & $91(14)$ & $28(13)$ & $<0.001$ \\
\hline Referral to physiotherapy & $492(23)$ & $141(23)$ & $133(25)$ & $154(23)$ & $53(24)$ & 0.93 \\
\hline Referral to pain clinic & $46(2)$ & $2(<1)$ & $15(3)$ & $0(0)$ & 29 (13) & $<0.001$ \\
\hline \multicolumn{7}{|l|}{ Follow-up, $n(\%)$} \\
\hline Discharge to GP & 821 (39) & $248(41)$ & $162(30)$ & $301(46)$ & 86 (39) & $<0.001$ \\
\hline Follow-up appointment & $208(10)$ & $47(8)$ & 100 (19) & $35(5)$ & $16(7)$ & $<0.001$ \\
\hline Follow-up pending results & $747(35)$ & $244(40)$ & $162(30)$ & $198(30)$ & $89(40)$ & $<0.001$ \\
\hline
\end{tabular}

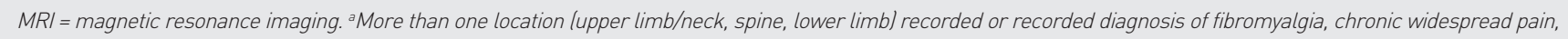
generalised osteoarthritis, or polymyalgia rheumatica. ${ }^{b}$ Comparison across location of problem.

Pain location and diagnosis

Most patients were diagnosed with a musculoskeletal problem considered suitable for an interface service: rheumatological problems (such as inflammatory arthritis, connective tissue disease or polymyalgia rheumatical and 'red flag' pathologies such as malignancy were infrequently encountered (58 patients, $3 \%$ and 11 patients, $<1 \%$ respectively). The lower limb was the site most frequently addressed in the CATS consultation 1656 patients, $31 \%, 95 \% \mathrm{Cl}=29 \%$ to $33 \%$ ), followed by the upper limb and neck 1607 


\begin{tabular}{|c|c|}
\hline \multicolumn{2}{|l|}{ Characteristic } \\
\hline \multicolumn{2}{|l|}{ Pain duration, $n[\%]$} \\
\hline Less than 3 months & $310(14)$ \\
\hline $3-12$ months & $650(30)$ \\
\hline $1-2$ years & 424 (20) \\
\hline $3-10$ years & $510(24)$ \\
\hline$>10$ years & $268(12)$ \\
\hline \multicolumn{2}{|l|}{ SF-36 domain, mean (SD) } \\
\hline Physical function & $36.5(12.0)$ \\
\hline Role limitations - physical & $35.7(12.1)$ \\
\hline Bodily pain & $34.4(8.6)$ \\
\hline General health & 41.5 (11.3) \\
\hline Vitality & 41.5 (11.5) \\
\hline Social functioning & $38.3(13.2)$ \\
\hline Role limitations - emotional & $40.0(15.4)$ \\
\hline Mental health & 43.3 (12.3) \\
\hline Major physical limitation, $n(\%)$ & $1651(76)$ \\
\hline \multicolumn{2}{|l|}{ Anxiety, $n(\%)$} \\
\hline Borderline (HADS 8-10) & $441(20)$ \\
\hline Probable case (HADS $\geq 11)$ & $619(29)$ \\
\hline \multicolumn{2}{|l|}{ Depression, $n(\%)$} \\
\hline Borderline (HADS 8-10) & $420(19)$ \\
\hline Probable case (HADS $\geq 11)$ & $380(18)$ \\
\hline \multicolumn{2}{|l|}{ Employment, $n(\%)$} \\
\hline Currently employed & 1136 (53) \\
\hline Time off work because of musculoskeletal problems in the preceding 6 months & $516[45]$ \\
\hline \multicolumn{2}{|l|}{ Ability to perform usual job, $n[\%]$} \\
\hline Currently performing usual job & $811(71)$ \\
\hline Working fewer hours & $65(6)$ \\
\hline Doing lighter duties & $125(11)$ \\
\hline On paid sick leave & $108[10]$ \\
\hline On unpaid leave & $27(2)$ \\
\hline
\end{tabular}

patients, $29 \%, 95 \% \mathrm{Cl}=27 \%$ to $31 \%$ ), spine (537 patients, 25\%, 95\% Cl = 23\% to $27 \%$ ), and multiple sites (221 patients, 10\%, 95\% $\mathrm{Cl}=9 \%$ to $12 \%$ ). The remaining patients were generally given specific diagnoses with no site specified, such as gout, inflammatory arthritis, and joint hypermobility.

The most common diagnoses at each site are shown in Table 2. Combining diagnoses across all joint sites, 487 participants (23\%, $95 \% \mathrm{Cl}=21 \%$ to $25 \%$ ) received a diagnosis of osteoarthritis.

\section{Investigations, interventions, referrals, and follow-up}

Investigations requested, interventions undertaken, onward referral, and plans for discharge and/or follow-up are shown in Table 3. One thousand and twelve participants ( $48 \%, 95 \% \mathrm{Cl}=45 \%$ to $50 \%)$ did not receive any investigations. X-ray was performed least frequently in the spine only group (8\% of the spine group received X-ray), whereas magnetic resonance imaging
(MRI) scans (37\%) were most frequently requested in this group. Blood tests were most frequently requested in the multiple site group (32\%). Both electrophysiological tests and diagnostic ultrasound were most frequently requested in the upper limb/neck only group. Corticosteroid injections were performed in 282 participants $113 \%, 95 \%$ $\mathrm{Cl}=12 \%$ to $15 \%$ ) and were most frequent in the upper limb/neck only group (25\%). Four hundred and ninety-two participants were referred to physiotherapy (23\%, 95\% $\mathrm{Cl}=21 \%$ to $25 \%$ ) but this did not appear to differ by pain location $(P=0.93)$. Referrals to pain clinics were infrequent $(2 \%)$ but were most frequent in those with pain at multiple sites $(P<0.001)$. Referral rates to orthopaedics and rheumatology were low (151 [7\%] and 60 [3\%] respectively).

Eight hundred and twenty-one participants were discharged to the care of their GP at this appointment $139 \%$, $95 \% \mathrm{Cl}=37 \%$ to $41 \%$ ). Discharge was highest in the lower limb group (46\%) and 
lowest in the spine group (30\%). A followup appointment in the interface service was arranged for 208 participants at this appointment $(10 \%, 95 \% \mathrm{Cl}=9 \%$ to $11 \%)$, with the decision to discharge or follow-up awaiting the results of investigations in a further 747 participants $135 \%, 95 \% \mathrm{Cl}=33 \%$ to $37 \%$ ).

\section{Health status and work absence}

Pain duration, physical limitation, anxiety, depression, and work absence are shown in Table 4. Pain duration was greater than 1 year in 1202 participants $(55 \%$, $95 \% \mathrm{Cl}=53 \%$ to $58 \%$ ). Individual SF-36 domain scores were below the general population norm of 50 for all eight domains. The largest deviations from the population norm were seen for the physical function, role limitations (physical), bodily pain, and social functioning domains. Major physical limitation was reported by 1651 participants (76\%, $95 \% \mathrm{Cl}=75 \%$ to $78 \%)$. One thousand and sixty participants $(49 \%, 95 \% \mathrm{Cl}=47 \%$ to $51 \%$ ) had symptoms of anxiety: 619 probable cases (29\%), with a further 441 borderline cases (20\%). Eight hundred $(37 \%, 95 \% \mathrm{Cl}=$ $35 \%$ to $39 \%$ ) had symptoms of depression: 380 probable cases (18\%) and 420 borderline cases (19\%). One thousand one hundred and thirty-six participants were in current employment (53\%], $95 \% \mathrm{Cl}=51 \%$ to $55 \%$ ). Of these, $516(45 \%, 95 \% \mathrm{Cl}=43 \%$ to $48 \%)$ had taken time off work in the last 6 months because of their musculoskeletal problem, and $325(29 \%, 95 \% \mathrm{Cl}=26 \%$ to $31 \%)$ were unable to do their usual job.

\section{DISCUSSION \\ Summary}

This is the first study highlighting the complexity of patients referred from primary care to multidisciplinary musculoskeletal CATS. The findings demonstrate the significant impact of musculoskeletal problems, with over three-quarters of patients reporting major physical limitation. The infrequency of 'red flag' pathologies emphasises the importance of effective clinical triage of referral letters, which, in the CATS used here, is carried out by clinically trained personnel. The underlying principle of this model of care, that most patients with musculoskeletal pain can be managed in a 'one-stop shop' without referral to expensive secondary care services, appears to be borne out by the small proportions requiring follow-up or referral to orthopaedics or rheumatology. However, this approach might be open to question, given the complexity of these patients, with high prevalences of chronic pain, impaired quality of life, and anxiety and depressive symptoms. More than half of patients required further investigation, $13 \%$ received local corticosteroid injections, and $23 \%$ were referred to physiotherapy. Despite high prevalences of chronic pain, anxiety, and depression, only $2 \%$ were referred to specialist pain clinics, suggesting that psychosocial issues are underrecognised and under-treated, and that CATS clinicians need to be appropriately trained in the biopsychosocial model of pain. Importantly, substantial absence from work was identified. Of those in current employment, almost half had taken time off work because of musculoskeletal problems in the preceding 6 months, and $29 \%$ were unable to perform their usual job.

\section{Strengths and limitations}

The study had a high response rate, with $73 \%$ of persons who attended their CATS appointment agreeing to participate. An additional strength is that it included consecutive adults attending the CATS, aged $\geq 18$ years, irrespective of their presenting musculoskeletal problems. This study demonstrates the feasibility of collecting outcome data for research purposes in routine clinical practice, supporting the collection of patient-reported outcome measures described in recent healthcare policy documents. ${ }^{5,14}$

There are two main limitations of the study. First, the study population was derived from one locality, so the findings might not be representative of patients attending CATS in other geographical regions. This locality is one of fairly high socioeconomic deprivation. Rates of obesity, anxiety, depression, and work disability might therefore reflect trends in the local population rather than being specific to this cohort. The prevalence of obesity in this cohort is above the UK national average, whereas the prevalence of smoking is consistent with the national picture. ${ }^{15}$ Differences between the configuration of CATS services and referral pathways in different areas might limit the generalisability of the study findings. Nevertheless, the CATS used was highlighted in the Musculoskeletal Services Framework as a successful model of interface care, ${ }^{6}$ and is broadly consistent with the design of musculoskeletal services proposed therein. Secondly, the study did not include a comparator cohort that would allow this musculoskeletal CATS to be compared to more traditional musculoskeletal services such as orthopaedics and rheumatology. Although this musculoskeletal CATS is the preferred local provider for patients with nonsurgical, non-inflammatory musculoskeletal problems, at the time of the study, direct 
referrals into rheumatology and orthopaedic clinics were possible, potentially reducing the generalisability of the findings. One further caveat is that the study did not collect data pertaining to waiting times to the first CATS appointment, which might influence attendance and psychosocial issues.

\section{Comparison with existing literature}

Owing to the novelty of musculoskeletal CATS in the UK, there are no suitable cohorts based at the primary-secondary care interface with which the study findings can be compared. A recent evaluation of a physiotherapist-led musculoskeletal clinical assessment service did not assess anxiety, depression, or work absence. ${ }^{16}$ The prevalences of anxiety and depression in the study cohort are higher than those reported in general population samples, ${ }^{17,18}$ and in those suffering from neck/upper limb pain. ${ }^{19}$ They are similar to studies of people consulting with musculoskeletal problems in primary care, ${ }^{20,21}$ and with musculoskeletal problems lincluding inflammatory arthritis) in secondary care. ${ }^{22-24}$ The findings are consistent with previous studies showing high levels of work absence in those consulting in primary care in the UK for back pain, ${ }^{20,25}$ and those suffering from low back pain in the Netherlands who are referred to rehabilitation centres. ${ }^{26}$ Overall, the study provides empirical evidence about the high frequency of anxiety, depression, and work absence in patients consulting with non-inflammatory musculoskeletal problems at the primary-secondary care interface, highlighting the importance of recognising and tackling these important issues in this setting.

Implications for research and practice

The high prevalences of chronic pain, anxiety, depression, and work disability provide insight into the nature and range of support services needed, and, crucially, the importance of providing appropriate training for health professionals to deliver a biopsychosocial model of care. The prevalence of work absence due to musculoskeletal problems supports the need for healthcare professionals to recognise retention in, or return to, work as a key indicator of the successful treatment of working-age people advocated by Working for a Healthier Tomorrow, ${ }_{1}^{4}$ and raises the question as to whether specific vocational rehabilitation programmes should be incorporated into care pathways at the primary-secondary care interface.

\section{Ethical approval}

South Staffordshire Local Research Ethics Committee (REC reference number: 07/ H1203/86) approved the study.

\section{Provenance}

Freely submitted; externally peer reviewed.

\section{Competing interests}

The authors have declared no competing interests.

\section{Acknowledgements}

The authors would like to thank the following people who contributed to the management and/or administration of the study, either at the Arthritis Research UK Primary Care Centre or Stoke-on-Trent PCT: Joanne Bailey, Helen Duffy, Tina Gilbert, Rhian Hughes, Zoë Mayson, Janet Ough, Diane Stanyer, Vicki Taylor, and Sue Weir. Dr Andrew Hassell led the funding application. The authors would also like to acknowledge the contribution of the research nurse teams at the Arthritis Research UK Primary Care Centre and Haywood Hospital, and the clinicians within Stoke-on-Trent PCT musculoskeletal and back pain interface services to data acquisition.

\section{Discuss this article}

Contribute and read comments about this article on the Discussion Forum: http://www.rcgp.org.uk/bjgp-discuss 


\section{REFERENCES}

1. Jordan K, Jinks C, Croft P. A prospective study of the consulting behaviour of older people with knee pain. Br J Gen Pract 2006; 56(525): 269-276.

2. Jordan K, Kadam U, Hayward R, et al. Annual consultation prevalence of regional musculoskeletal problems in primary care: an observational study. BMC Musculoskelet Disord 2010; 11(1): 144.

3. Confederation of British Industry. On the path to recovery: absence and workplace health survey 2010. London: Confederation of British Industry, 2010. http://uww.midlandconstructionsafety.com/index_files/pdf/aspire3.pdf laccessed 11 Dec 2012).

4. Black C. Working for a healthier tomorrow. London: TSO, 2008. http://www.dwp. gov.uk/docs/hwwb-working-for-a-healthier-tomorrow.pdf laccessed 11 Dec 2012).

5. Department of Health. Equity and excellence: liberating the NHS. Cm7881. London: DoH, 2010. www.dh.gov.uk/prod_consum_dh/groups/dh_ digitalassets/dadh/den/_aps/documents/digitalasset/dh_117794.pdf laccessed 11 Dec 2012).

6. Department of Health. The Musculoskeletal Services Framework. A joint responsibility: doing it differently. London: DoH, 2006. http://www.dh.gov.uk/ prod_consum_dh/groups/dh_digitalassets/dadh/den/documents/digitalasset/ dh_4138412.pdf (accessed 11 Dec 2012).

7. Roddy E, Zwierska I, Dawes P, et al. The Staffordshire Arthritis, Musculoskeletal, and Back Assessment (SAMBA) study: a prospective observational study of patient outcome following referral to a primary-secondary care musculoskeletal interface service. BMC Musculoskelet Disord 2010; 11(1): 67.

8. Ware JE, Jr, Sherbourne CD. The MOS 36-item Short-Form Health Survey (SF-36). I. Conceptual framework and item selection. Med Care 1992; 30(6): 473-483.

9. Zigmond AS, Snaith RP. The Hospital Anxiety and Depression Scale. Acta Psychiatr Scand 1983; 67(6): 361-370.

10. de Vet HC, Heymans MW, Dunn KM, et al. Episodes of low back pain: a proposal for uniform definitions to be used in research. Spine 2002; 27(21): 2409-2416.

11. Department for Communities and Local Government. The English indices of deprivation 2010. London: Department for Communities and Local Government, 2011. https://www.gov.uk/government/uploads/system/uploads/attachment_ data/file/6871/1871208.pdf (accessed 11 Dec 2012).

12. Rose MS, Koshman ML, Spreng S, Sheldon R. Statistical issues encountered in the comparison of health-related quality of life in diseased patients to published general population norms: problems and solutions. J Clin Epidemiol 1999; 52(5): 405-412.

13. Dunn KM, Jordan K, Lacey RJ, et al. Patterns of consent in epidemiologic research: evidence from over 25,000 responders. Am J Epidemiol 2004; 159(11): 1087-1094.

14. Darzi A. High quality care for all. NHS Next Stage review final report. Cm7432. London: Department of Health, 2008. http://www.dh.gov.uk/en/ Publicationsandstatistics/Publications/PublicationsPolicyAndGuidance/ DH_085825 (accessed 11 Dec 2012).

15. Health and Social Care Information Centre. Health Survey for England - 2011. Adult Trend Tables. http://www. ic.nhs.uk/searchcatalogue?productid=10152\&topics= 1\%2fPublic+health\%2fLifestyle\&sort=Relevance \&size=10\&page=1\#top (accessed 8 Jan 2013).

16. Sephton R, Hough E, Roberts SA, Oldham J. Evaluation of a primary care musculoskeletal clinical assessment service: a preliminary study. Physiotherapy 2010; 96(4): 296-302.

17. Crawford JR, Henry JD, Crombie C, Taylor EP. Normative data for the HADS from a large non-clinical sample. Br J Clin Psychol 2001; 40(4): 429-434.

18. Lisspers J, Nygren A, Soderman E. Hospital Anxiety and Depression Scale (HAD): some psychometric data for a Swedish sample. Acta Psychiatr Scand 1997; 96(4): 281-286.

19. van der Windt $D$, Croft $P$, Penninx $B$. Neck and upper limb pain: more pain is associated with psychological distress and consultation rate in primary care. $J$ Rheumatol 2002; 29(3): 564-569

20. Dunn KM, Croft PR. Classification of low back pain in primary care: using 'bothersomeness' to identify the most severe cases. Spine 2005; 30(16): 18871892.

21. Mallen CD, Peat G. Screening older people with musculoskeletal pain for depressive symptoms in primary care. Br J Gen Pract 2008; 58(555): 688-693.

22. Keeley P, Creed F, Tomenson B, et al. Psychosocial predictors of health-related quality of life and health service utilisation in people with chronic low back pain. Pain 2008; 135(1-2): 142-150.

23. Hider SL, Tanveer W, Brownfield A, et al. Depression in RA patients treated with anti-TNF is common and under-recognized in the rheumatology clinic. Rheumatology 2009; 48(9): 1152-1154.

24. Healey EL, Haywood KL, Jordan KP, et al. Ankylosing spondylitis and its impact on sexual relationships. Rheumatology 2009; 48(11): 1378-1381.

25. Wynne-Jones G, Dunn KM, Main CJ. The impact of low back pain on work: a study in primary care consulters. Eur J Pain 2008; 12(2): 180-188.

26. Smeets RJ, Wittink H, Hidding A, Knottnerus JA. Do patients with chronic low back pain have a lower level of aerobic fitness than healthy controls? Are pain, disability, fear of injury, working status, or level of leisure time activity associated with the difference in aerobic fitness level? Spine 2006; 31(1): 90-97. 